\title{
Tradición clásica y utopía en La caída del águila, de Carlos Gagini'
}

\section{(Classical Tradition and Utopia in La caída del águila, by Carlos Gagini)}

\section{Minor Herrera Valenciano ${ }^{2}$}

Universidad de Costa Rica, Costa Rica

\begin{abstract}
RESUMEN
Carlos Gagini plantea la construcción de un espacio utópico, la isla del Coco. La novela La caída del águila evoca, a partir de una lectura desde la tradición clásica, el mito de la Atlántida, ejemplo de espacio utópico en la Antigüedad. El presente trabajo establece y analiza la relación entre el mito atlántico, mencionado en los diálogos platónicos Critias y Timeo y la idea de espacio utópico desarrollado por el novelista costarricense.
\end{abstract}

\begin{abstract}
Carlos Gagini proposes the construction of a utopian space, Coco's Island. His novel La caída del águila [The Fall of the Eagle] evokes, in a reading from the classical tradition, the myth of Atlantis, an example of a utopian space in antiquity. Thus, this analysis establishes the relationship between the Atlantis myth, mentioned in Plato's dialogues Critias and Timaeus and the idea of a utopian space developed by this Costa Rican novelist.
\end{abstract}

Palabras clave: tradición clásica, utopía, Atlántida, Platón, narrativa costarricense, Carlos Gagini

1 Recibido: 13 de mayo de 2018; aceptado: 17 de setiembre de 2018.

2 Sección de Filología, Universidad de Costa Rica. Correo electrónico: www.minorj2007@hotmail. com. Este trabajo forma parte del proyecto de investigación «La Construcción discursiva de la utopía en la obra Literaria de Carlos Gagini», con el código n. ${ }^{\circ}$ 836-B6-06, del Centro de Investigaciones sobre Diversidad Cultural y Estudios Regionales, Universidad de Costa Rica, Sede de Occidente.

LETRAS 64 (2018), ISSN 1409-424X; EISSN 2215-4094

Doi: http://dx.doi.org/10.15359/rl.2-64.3

www.revistas.una.ac.cr/index.php/letras 
Keywords: classical tradition, utopia, Atlantis, Plato, Costa Rican narrative, Carlos Gagini

...contemplaba en su imaginación a las naciones unidas, no por la presión de la fuerza sino por los lazos del amor.

CARlos Gagini

La caída del águila

\section{Introducción}

Numerosos escritores han dedicado sus vidas para imaginar y perseguir utopías-atlántidas (Erasmo de Rotterdam, Tomas Moro, Francis Bacon) en textos cuya finalidad es mostrar una posibilidad de mejoramiento; lugares perfectos según una concepción individual, pero que, en el fondo, tienen la intensión de ser un proyecto colectivo en procura del bien común. Unido a lo anterior, la utopía sería la mejor de las repúblicas posibles, debido a que en ella el ser humano (utopía humanista) alcanzará la perfección, la bienaventuranza y con ello la felicidad, esta última comprendida como el logro de la vida en plenitud y la satisfacción de haber obtenido todo aquello a lo que aspiraba. Al respecto, la Atlántida de Platón, de los diálogos de Timeo y Critias en relación con la isla del Coco, descrita por Carlos Gagini en La caída del Águila (1920), presentando vestigios de tradición clásica. Para el escritor, en voz del personaje Roberto Mora, no existe mejor lugar para iniciar su proyecto revolucionario que una isla en la que se pueda alcanzar la plenitud humana, lugar del que el personaje afirma «no habrá pobres, no revoltosos, ni criminales; la humanidad sería una familia y realzaría plenamente su destino, esto es, vivir, pues para ello fue engendrada.... $\rangle^{3}$.

La literatura costarricense de finales del siglo xIX y principios del xx no escapa de la posibilidad de mostrar utopías. Es posible notar

3 Carlos Gagini, La caída del águila (San José: Editorial Costa Rica, 1981); en adelante los números de página se indicarán entre paréntesis en el texto. 
cómo Gagini plantea la construcción de un espacio utópico, la isla del Coco, en su texto La caída del águila, el cual evoca, a partir de una lectura desde la tradición clásica, al mito de la Atlántida, claro ejemplo de espacio utópico en la Antigüedad. Por lo tanto, el presente trabajo tiene como objetivo establecer la relación entre el mito atlántico, mencionado en Critias y Timeo de Platón, el concepto de utopía y la idea de espacio utópico desarrollado por Gagini.

Se busca mostrar la relación que existe entre el deseo de perfección (político, humano) en una sociedad y el mito de la Atlántida de Platón. Para ello conviene acudir a fuentes tanto históricas como literarias para fundamentar el mito platónico como utopía que posibilite puntos de encuentro, a su vez, con el texto de Carlos Gagini. El ideal de progreso científico y de excelencia mostrado en el mito platónico ha viajado mucho más lejos del momento de su creación, hasta considerarse principio de la utopía y, por esto, pervivir (tradición clásica) en La caida del águila.

\section{La tradición clásica}

Cuando se trata la tradición clásica, se alude tanto a la pervivencia de la cultura clásica en Occidente (textos, lengua, mitología, concepciones filosóficas, entre otros), como al método (de los Estudios del Mundo Antiguo) que se hace cargo de reconocer y analizar dicho objeto de estudio. El término que mejor se acuñó fue el utilizado por Highet, en 1949: The Classical Tradition. En español, lo empleó Isidoro Muñoz Valle, en 1964, en La tradición clásica en la lírica de Bécquer. Según García Jurado 4 , lo más probable es que Highet haya ideado el término, a partir del trabajo de Doménico Comparetti, titulado Virgilio nel medioevo ${ }^{5}$. Comparetti, citado por Laguna ${ }^{6}$,

4 Francisco García Jurado, «¿Por qué nació la juntura “Tradición Clásica?”. Razones historiográficas para un concepto moderno», Cuadernos de Filología Clásica. Estudios Latinos 27, 1 (2007): 161-192.

5 Domenico Comparetti, Virgilio nel medio evo (Firenze: Nuova Italia, 1967).

6 Gabriel Laguna Mariscal, «¿De dónde procede la denominación Tradición Clásica?», Cuadernos de Filología Clásica. Estudios Latinos 24, 1 (2004): 83-93. 
suponía que lo que correspondía a la tradición clásica debía ser visto como una herencia o «legado literario grecolatino pagano, tal como se transmitió en la Edad Media». Tal como se observa en el siguiente esquema, Comparetti se valió de lo que hoy se considera el método positivista, es decir, el paradigma de «A» en «B».

\section{Elemento «A» en Elemento «B»}

Tradición clásica $\longleftrightarrow$ Antiguo $\longleftrightarrow$ Moderno $\longleftrightarrow$ Mención directa

Como se observa, «A» es el elemento clásico grecolatino y «B» el texto moderno en el que se alude directamente al anterior. Para García Jurado (2007), Highet ofreció una perspectiva más elaborada de la tradición clásica que la mostrada por Comparetti ${ }^{7}$ y con esto establece el punto de partida para un sinnúmero de publicaciones ${ }^{8}$ posteriores las cuales conjuntaban los métodos tradicionales con visiones modernas, ampliando desde luego, la noción positivista de «A» en «B», de manera que los puntos de encuentro entre los textos antiguos y los modernos no solo partiesen de posibilidades de estudios novedosas, sino aquellas en la que no puede pasarse por alto la capacidad de selección y la reintegración que los propios receptores modernos poseen de las obras que leen.

El autor moderno puede valerse de la tradición clásica en un texto, aunque no esté consciente del uso de pasajes míticos o de la incorporación de elementos clásicos (personajes, metáforas, ideas, nociones sobre diversos temas, posiciones filosóficas, entre otros)

$7 \quad$ Comparetti, 119.

8 Es posible encontrar algunas investigaciones que revelan la importancia del estudio de la tradición clásica para comprender el sentido cabal de muchos textos, ejemplo de ello son: G. Highet, La tradición clásica. Influencias griegas y romanas en la literatura occidental (México: Fondo de Cultura Económica, 1954); José S. Lasso de la Vega, «El mito clásico en la literatura contemporánea», Actas del II Congreso Español de Estudios Clásicos (Madrid, 1964) 405-466; I. Rodríguez Alfageme y A. Bravo García, eds., Tradición Clásica y siglo xx (Madrid: Ediciones Coloquio, 1986); Francisco García Jurado, Teoría de la Tradición Clásica. Conceptos, historia y métodos (México: Editorial UNAM, 2015). 
tomadas de textos clásicos (griegos o latinos), pues las estructuras míticas de su pensamiento hacen que, de forma inconsciente, las incorpore en la trama de la nueva producción.

Pueden considerarse a los clásicos como modelos y punto de partida temáticos para el desarrollo de nuevos textos $\mathrm{y}$, con estos, nuevas interpretaciones, ya que la tradición clásica es el «reencuentro con la reescritura que actualiza cada uno de los afluentes literarios de los que se nutre»" ${ }^{9}$. No se trata de dar con la mención directa de elementos clásicos grecolatinos sino de localizar los ecos clásicos que han perdurado en los textos modernos, las ideas comparables con ideas antiguas, pero que se reestructuran para cumplir con objetivos solamente realizables en el nuevo contexto, en el del texto moderno.

Desde la Antigüedad, el mito se estableció como punto de partida para el desarrollo de obras literarias y la construcción discursiva de la utopía. No sería posible entender cómo se construyen imaginarios esperanzadores cimentados en los ideales de una sociedad perfecta $\mathrm{o}$ la comunión de los pueblos (en torno de un mismo ideal) sin recursos provenientes de la mitología, por ejemplo, como los que aporta Platón, al referirse a la Atlántida, en sus diálogos.

En el siglo Iv a.C, Platón ${ }^{10}$ escribe el Timeo y el Critias. En ellos, por vez primera, se presenta el mito de la Atlántida: un asentamiento cuya constitución política, su ubicación geográfica y su construcción arquitectónica son emplazadas por el filósofo unos nueve mil años antes de la ostentación del poder por parte del rey Solón (640 a. C. al 558 a. C.), reformador político y legislador de Atenas, y que justifica su existencia en documentos espurios pertenecientes a sacerdotes de la ciudad llamada Sais, situada en el Bajo Egipto.

Platón acude a ciertos elementos que dotan de verosimilitud lo narrado y, por lo tanto, dará pie a las más inusuales investigaciones y planteamiento de ideas en relación con laAtlántida. Este procedimiento

9 Francisco García Jurado, Teoría de la Tradición Clásica. Conceptos, historia y métodos (México: Editorial UNAM, 2015) 132.

10 Platón, Diálogos I, II, III, IV. Trad. Mariángeles Durán y Francisco Lisi (Madrid: Gredos, 1992). 
será indispensable en relación con el establecimiento de las utopías, en tanto, son posibilidades, verosímiles, de alcanzar un ideal, aunque, en la práctica, no se quede más que en un deseo. De este modo, se refiere a textos desconocidos, salvo por Sócrates (los documentos de los sacerdotes egipcios de Sais), e incorpora en los diálogos una serie de personajes cuya existencia se comprueba históricamente (Critias, Solón y Drópidas) y para mantener el enigma sitúa la ciudad en un tiempo remoto, mítico (como lo comenta Pierre Vidal-Naquet) y en un océano del que se poseen pocas o nulas referencias durante el siglo IV a.C.

Así, desde su creación en los diálogos platónicos, la ciudad perdida de la Atlántida se ha convertido en una cuestión, cuyas interrogantes son innumerables, así como los intentos por darles respuesta. De ella, se han leído fabulaciones, alegorías filosóficas, paraísos perdidos y, por supuesto, utopías (humanísticas, políticas, sociales, etc.), desde las que muchos autores modernos, gracias a la larguísima tradición clásica de este mito, han vislumbrado sus propios proyectos utópicos, como se verá con la obra La caída del águila de Carlos Gagini.

\section{Platón y la Atlántida: contextualización}

Timeo y Critias 11 los escribió Platón en el ocaso de su vida y de su actividad literaria; pudo haber sido entre los años 369 al 348 a.C. A la Atlántida se la concibe como un espacio utópico; una ciudad levantada con una arquitectura y un sistema político «perfecto» ${ }^{12}$, cuya estructura social (equidad) debería ser el modelo de las urbes sucesoras, aunque no así la codicia de poder de sus gobernantes, hecho que

11 Platón, Diálogos I, II, III, IV. Trad. Mariángeles Durán y Francisco Lisi (Madrid: Gredos, 1992).

12 Esta idea de teorizar un sistema político perfecto fue una constante en el pensamiento platónico. Uno de los mejores ejemplos de ello, son los libros de la República, ya que su producción abarca dos grandes etapas de la vida de Platón, a saber, su juventud y madurez. Una lectura atenta muestra cómo el libro primero corresponde más a su fase de juventud, mientras que los demás a la madurez. Además, puede indicarse que Las Leyes (el cual es de la etapa de vejez, como el Timeo y el Critias) constituye un último intento de dicha constante, por cuanto que trata de concebir nuevamente un orden político perfecto. 
devendrá en su desmoronamiento. Además, su existencia es datada nueve mil años antes del reinado de Solón de Atenas.

En la datación subyace un problema de temporalidad, porque se ubicaría en un tiempo mítico, un tiempo que no puede cronometrarse; anterior, incluso, a los reyes míticos y fundadores de Atenas (Cécrope, Erecteo, Egeo y Teseo), como lo señala Platón, lo que convertiría el relato en mera ficción filosófica.

No obstante, esa cronología estaría desprovista de importancia, ya que la ficción filosófica, impuesta al relato de la Atlántida, se traduciría más bien como alegoría, un ideal de sociedad. Aunado a esto, las genealogías expuestas tanto en Timeo como en Critias, bien podrían tratarse como fantasía literaria, porque estas en muy poco distan de los cuentos para niños ${ }^{13}$.

Los mitos expuestos por Platón en sus diálogos son numerosos (sobre el alma, el amor, la vida en el Más allá, el andrógino, etc.); sin embargo, a ninguno, con excepción de la Atlántida, se le ha enmarcado en el mundo real. Esta necesidad por establecer el sitio justo donde se desarrolló la avanzada civilización Atlántida, nació y se desarrolló en la Antigüedad y pervive hasta hoy gracias a la tradición clásica. Muchos estudiosos del Mundo antiguo, según Díaz Tejera ${ }^{14}$, la han situado en Marruecos, Nigeria, Golfo de México, Creta, Cuba, Tartesos, entre otras muchas ubicaciones posibles, pero con bases sustantivamente débiles.

Son muchos los tratados sobre el mito de la Atlántida, por lo que formular un estado de la cuestión sobre el asunto es muy difícil. Lo posible es determinar dos corrientes de estudios: las que ven en el relato de la Atlántida un discurso verdadero desde punto de vista de la historia y las que ven un relato de ficción, que se reconstruye en nuevos textos como será en el caso de La caída del águila de Gagini.

13 «Las genealogías de los vuestros que acabas de exponer poco se diferencian de los cuentos de niño», Timeo, 23b. La traducción que se sigue es la de Mariángeles Durán y Francisco Lisi (Gredos, 1992).

14 Alberto Díaz Tejera, «El relato platónico de la Atlántida. Comentario a los diálogos Timeo y Critias», Anuario de Estudios Atlánticos 42, 2, (1996): 209-242. 
Entre los que lo consideran un relato verdadero, es posible distinguir en la Antigüedad a Crántor ${ }^{15}$ y Posidonio. Entre quienes consideraban laAtlántida como un relato histórico se encuentran Donelly (Atlántida: el mundo antediluviano, 1882), considerado el padre de los trabajos arqueológicos (pseudoarqueología ${ }^{16}$ ) relacionados con la ciudad platónica. Lewis Spencer, discípulo de Donelly escribe sobre cómo la Atlántida estaría ubicada en algún sitio, en medio del Atlántico, cerca de lo que hoy sería el Golfo de México, mientras que A. Schulten (1922), citado por Díaz Tejera, la situaba en Tartesso ${ }^{17}$ (en el triángulo formado por Huelva, Sevilla y Cádiz).

Entre quienes han considerado la Atlántida como ficción filosófica de Platón, se encuentran en la Antigüedad Proclo (alumno de Platón), Aristóteles y Plutarco. Algunos notables filólogos del siglo xx consideran la Atlántida pura invención utópico-platónica, quien más trataron el tema fueron Rohde $^{18}$ y Frutiger ${ }^{19}$.

Así, las posibilidades para el relato de la Atlántida ${ }^{20}$ son muchas: en primer lugar, la de que fuera un relato histórico; en segundo lugar, que se tratase de una transposición poética con base tangible; en tercer lugar, que fuese tan solo una alegoría filosófica y, finalmente, que fuera una ficción literaria.

\section{Timeo, Critias: diálogos sobre la Atlántida}

De una pormenorizada lectura de los diálogos de Platón es posible percatarse de la complementariedad entre la República, Timeo y Critias. En primer lugar, es innegable la codependencia existente entre

15 Primer comentarista de Platón, según Díaz Tejera.

16 Se trataría de trabajos e investigaciones arqueológicas que no llegan a conclusiones convincentes, o bien, que se valen de fuentes poco confiables o acreditadas.

17 Y lo piensa así porque a) Tartesos está en Occidente como la Atlántida; b) los ramales fluviales del Betis o Guadalquivir estarían en consonancia con los canales de la Atlántida; c) la relación de uno de los reyes atlánticos, Gádeiros, con Gádeira, Cádiz; y d) las riquezas de metales en una y otra ciudad. Pero, a pesar de los esfuerzos de Schulten, Tartesos es todavía una hipótesis, no era una isla y no estaba en medio del mar exterior (Díaz Tejera, 1996).

18 Erwin Rohde, Los griegos, los romanos y sus precursores (Madrid: Escolar, 2015).

19 P. Frutiger, Los mitos de Platón (New York: New York University Press, 1976).

20 Díaz Tejera, 212. 
Timeo y Critias; el primero anuncia el segundo, o bien, el segundo es continuación del primero. Platón trata la idea de un gobierno perfecto en la República; asimismo, en Timeo se resumen los principales argumentos expuestos en dicho texto, además de ofrecer una introducción al tema de la Atlántida mediante la lucha contra los atenienses y su triunfo ante el poder imperante de los atlantes. En este texto, en la constitución de una nueva Atenas radica el cuestionamiento de cómo se podría desarrollar una urbe, cuya estructura política y social fuese perfecta (en el sentido de conocimiento, justicia y equidad). Para responder al cuestionamiento, en dicho diálogo, se realiza una amplia descripción idealista de Atenas en la que se pondera el acercamiento que sus pobladores tienen a las distintas artes y disciplinas, pero principalmente a la filosofía, vista esta como eje fundamental de «todo».

En Critias, la relación entre Atenas y la Atlántida es más notoria. La descripción es mucho más detallada; no obstante, queda inconclusa la narración, ya que no se cuenta el relato épico, que apuntaba ser la parte esencial del diálogo. Ante la ausencia del final de Critias, saltan interrogantes y sus respectivas hipótesis, que van desde las que exponen la idea de un final perdido, hasta el fallecimiento de su autor antes de concluir la obra. Sin embargo, la aseveración más aceptada es que Platón haya desistido de escribir el final de esta obra, para dedicarse a escribir las Leyes, cuya trascendencia filosófica y política sería más reconocida.

\section{Timeo (20 d. 27 c): primeros datos del mito}

Los protagonistas son cuatro: Sócrates, Critias, Timeo y Hermócrates. El tema de discusión: cuál es el «ideal» en cuanto a organización política. Este diálogo continuaría, con la intención expresada en la República, de concebir tal sociedad ideal, de la que se hablará más adelante. Así, la Atlántida sería la respuesta a ese ideal. De dicha cuidad se comenta que se opuso en algún momento de la historia a la ciudad de Atenas (la primigenia), cuyo único registro había sido guardado por los egipcios. 
Como la mayoría de relatos de la Antigüedad, la leyenda de la Atlántida había llegado a Sócrates por trasmisión oral y breves escritos pasados a lo largo de muchas generaciones; así, esta historia fue conocida por Solón, Drópidas, Critias (el viejo) y $\mathrm{Critias}^{21}$, quienes a su vez eran parientes de Platón.

De acuerdo con Platón, cuando Critias todavía era un niño (de diez años), su abuelo, Critias (el viejo o el mayor), quien debía de rondar los noventa años, le contó una leyenda que a él le había referido su padre Drópidas, esta narración ponía como protagonista a Solón, quien había realizado un viaje a Egipto. Permaneció un tiempo en Sais donde aprendió de uno de los sabios ancianos de la región, la historia de la Atenas primigenia y, asimismo de la Atlántida. Dicha historia fundamentada en escritos que habían sido conservados por los sacerdotes saíticos de Egipto ${ }^{22}$. Solón se percata de que Atenas, en tiempos casi imposibles de datar, había realizado la proeza más destacada y valiosa: la victoria ante un imperio que intentaba extenderse desde en Atlántico hacia Europa y sobre Asia. El imperio se asentaba en una isla, Atlántida, ubicada frente las Columnas de Hércules; su tamaño era mayor que Asia.

Dicha «potencia» era dominadora desde el norte de África hasta Egipto y de una gran parte de Europa, Tirrenia. Aunado a esto, el intento por imperar sobre los helenos. Atenas convocó a los pueblos griegos, que acudieron en gran cantidad; sin embargo, fueron abandonando la batalla hasta dejarla completamente sola. No obstante, los atenienses combatieron solos y alcanzaron finalmente la victoria, a pesar de su inferioridad numérica. Con esto, liberaron a los pueblos reprimidos por los Atlantes, quienes, dejaron de cultivar las artes y cuyos gobernantes se dejaron llevar por el deseo de poder y expansión, hecho que contribuyó a que dejara de ser un ideal.

21 Critias ya había aparecido en otro de los diálogos de Platón, se trata de Cármides o de la sabiduría, pero en Critias él será protagonista y narrador de la historia de la Atlántida.

22 Alberto Díaz Tejera señala que, a diferencia de los griegos que luego de cataclismos olvidaban los escritos e iniciaban una nueva historia; los egipcios conservaban todo por más antiguo que fuese, pues eran considerados el tesoro de la sabiduría. 
Finalmente, la Atlántida desaparecería en un día y una noche producto de un cataclismo, un terremoto y un diluvio que la habrían arrasado.

\section{Critias: la Atlántida en detalle}

En este diálogo participaron los mismos interlocutores del diálogo anterior. Esta vez Critias ahonda en el relato de la Atlántida. Su descripción se enriquece mediante la introducción de detalles históricos, geográficos, políticos, sociales, míticos y religiosos que dotan de verosimilitud al relato y extienden la posibilidad de la existencia de dicha cuidad en tiempos remotos; sin embargo, la obra está inconclusa. En este diálogo se conoce que los escritos de Solón, traídos de Sais y que contenían la historia de la victoria ateniense sobre los atlantes, se encuentran en la casa de Critias quien, de joven, dedicó tiempo a su detallado estudio. Este dato amplía la información presente en Timeo, donde no aparece nada como esto. Un dato llamativo es que Critias hace algunas aportaciones filológicas, ya que utilizará transcripciones griegas para los nombres de los atlantes. Ahí mismo se afirma que los egipcios habían traducido nombres atlantes a egipcio y que Solón hizo lo mismo del egipcio al griego para escribir el relato de la Atlántida $\mathrm{y}$ que fuese legible para cualquier griego.

En el relato, Critias dice que han pasado cerca de nueve milenios desde el instante en que el dio comienzo la guerra entre los atlantes y atenienses. En esto introduce un relato mítico: Poseidón dueño de la Atlántida. Cuando la Tierra se reparte entre los dioses olímpicos, la Atlántida es entregada a Poseidón quien, en unión con Clito, engendrarán a cinco generaciones de hombres, todos mellizos. Con estos hombres estableció una monarquía a cargo de Atlas, el cual había sido el primero en nacer. Los demás (Eumelo, Anferes, Evaimon, Mneseas, Autóctono, Elasippo, Mestor, Azaes y Diaprepés) serían vasallos del mayor ${ }^{23}$.

23 Díaz Tejera señala que es posible que haya cierta intención en el hecho de haber seleccionado los nombres de los atlantes, tomados de los poemas homéricos, con excepción de Diaprepés, quien y 
Critias describe cómo Poseidón erigió la isla, la embelleció, la retiró a un lugar especial o estratégico y la dotó de muros fortificados para hacerla perdurar. Además, hace referencia a los recursos naturales con los que contaba la Atlántida: metales, madera, animales, lagos, pantanos, ríos, montañas, llanuras, esencias aromáticas, frutos y cereales. Posteriormente, menciona cómo los habitantes de la isla la llenaron de grandeza, gracias a que la urbanizaron con templos, palacios, puertos, canales, murallas de cobre, estaño y oricalco (metal mitológico, cuyo valor es el segundo más valioso); fuentes, estanques, piscinas y varios puertos amurallados que rebosaban de viviendas, barcos y mercaderes. Además, Critias menciona algunas particularidades sobre la cultura atlante, por ejemplo, carreras de caballos, el juramento de fidelidad entre sacerdotes y reyes y, el más importante, atrapar a un toro y sacrificarlo en el templo consagrado a Poseidón ${ }^{24}$.

Según Critias, uno de los posibles motivos que desembocarían en la guerra atlante-ateniense sería el hecho de que Atlántida, sus habitantes, hubiesen abandonado la naturaleza divina concedida, desde su origen por Poseidón y, en cambio, hubiesen incurrido en el terrible error de mezclarse (mestizaje) con los humanos. Antes de este cruce, los atlantes atendían las leyes, eran buenos, racionales, éticamente correctos, en fin, llenos de virtudes. Luego de que se mezclaran con los humanos, caerían en el deseo de poder, en la insensatez e incluso se creían autosuficientes ( $\sin$ necesidad de divinidad). Por tales motivos Zeus convoca a los Olímpicos para castigar el atrevimiento de los atlantes; sin embargo, en este momento la narración se ve truncada, pues el texto se corta, no obstante; es entendible que lo subsiguiente se trataría de la guerra.

aparecía en el «Pseudo Heráclito» asociado a las Herpérides, leyendas relacionadas por Hesíodo con el mito de Atlas.

24 Esto pudo hacer que, en principio, se considerara que Atlántida podría ser Creta. 


\section{La Atlántida: reflejo de una utopía}

Contextualizado el mito de la Atlántida, ¿por qué este mito puede representar una utopía? Para Eliade ${ }^{25}$, el mito es una historia que relata un acontecimiento que ha tenido lugar en el tiempo primordial, el tiempo fabuloso de los comienzos. Cuenta cómo una realidad ha venido a la existencia, sea esta la realidad total, el cosmos, o solo un fragmento: una isla, un comportamiento humano, una institución. Por su parte, la utopía puede ser concebida como un ideal y, al mismo tiempo, como un lugar que no existe, una fantasía de lugar, como un proyecto, deseo, doctrina o sistema, cuya realización es imposible, es ficcional y que, desde el mismo instante de su formulación, es una idea y es justo aquí, en la delgada línea que divide realidad y ficción, que se encuentra la relación entre el mito atlántico y la utopía.

La Atlántida como mito, una ciudad preclara, que por el deseo de poder de sus gobernantes viene a menos hasta desaparecer por el enfado de las divinidades tutelares y es por esta razón que representa una utopía, pues, según Ortega y Gasset ${ }^{26}$, contiene en sí todos los componentes del mito conjuntados en una serie de símbolos que remite al deseo utópico, es decir, al sueño irrealizable de un ideal (un buen lugar) o a la ficción de un lugar que no es tal: la perfección representada por su geografía concéntrica, el resguardo divinal y las islas, cuya alusión son presagios de unión y equidad y que, además, como lo dice Vidal Naquet ${ }^{27}$, podrían ser vistas como sitios hermosos que han venido a menos porque se han dejado encantar por lo foráneo y abren sus puertos demasiado, al punto de no reconocerse a sí mismas.

La Atlántida es el modelo de sociedad perfecta, ejemplificación de la evolución de una civilización que aspira a la felicidad y que acaba por envilecerse. La referencia de Platón sobre el mito de tal

25 Mircea Eliade, Mito y realidad (Barcelona: Labor, 1992).

26 José Ortega y Gasset, «Las Atlántidas». Revista de Occidente X, 1 (1963): 91-112.

27 Pierre Vidal Naquet, La Atlántida: pequeña historia de un mito platónico. Traducción de María del Mar Ilinares García (Madrid: Akal, 2011). 
ciudad parece constituir un mundo idílico, es decir, la utopía de una sociedad perfecta, como la que había descrito con detalle en la República, se ajusta a las utopías del mundo antiguo, porque, al igual que en la Utopía de Tomás $\mathrm{Moro}^{28}$, con ella se alude a lo deseable, pero irrealizable. Para Platón, la Atlántida es un posible modelo narrativo para la conformación de la ciudad ideal que serviría para mostrar cómo debería ser organizada una ciudad para su correcto funcionamiento y en la que sus habitantes puedan llegar a ser plenamente personas.

A continuación, para concretar la relación, se mostrarán algunas similitudes entre la ciudad ideal de Platón y lo que sería una utopía, según el propio iniciador del término, Tomás Moro: en primer lugar, es posible apreciar que el diálogo es la forma que ambos autores eligen para presentar sus propuestas y, además, su contenido general se resume en dilucidar la manera ideal con la que una ciudad puede regirse y construirse. No obstante, son muchas más las similitudes presentadas, por ejemplo, en cuanto a la educación, para ambos es primordial; sin embargo, se trataría de un privilegio de unos pocos aristócratas, a los que llama «guardianes», estamento de donde surgirán los futuros gobernadores. Moro plantea, en contraste con Platón, una educación integral y pública, sin las limitaciones que las distintas clases sociales pudiesen acarrear. Tal educación daría inicio desde la primera infancia, cuando los niños aprenden lo que sus padres hacen, unido a un aprendizaje fundamental: la agricultura (este es una obligación). Luego aprenderían letras, gracias a lecturas públicas al amanecer, antes de las labores diarias y otras disciplinas para las que fuesen especialmente escogidos.

En cuanto a las instituciones públicas, estarían advocadas a reducir la carga laboral de los ciudadanos lo más posible, para que estos tengan tiempo de cultivar su inteligencia, ya que en esto yace la auténtica y absoluta felicidad. Así, el gobierno en ambos autores estaría regido por letrados. Moro llama a los regentes Sifograntes,

28 Tomás Moro, Utopía (Madrid: Akal, 1998). 
que están eximidos del trabajo; su obligación es inspirar a los demás a alcanzar la felicidad y la ilustración. Si alguno defrauda a quienes han puesto su esperanza en él, se le rebajará a realizar labores pesadas y toscas. Puede suceder lo opuesto: si alguno de los que realiza trabajos manuales cultiva las letras u otras disciplinas y las aplica para su vida, podrá ser ascendido hasta convertirse en uno de los gobernantes elegidos. Esto se parece bastante a la sofocracia de Platón, con la que gobernarían quienes cifrasen en el estudio de la filosofía, los propósitos de su vida. Así, más que por elección popular, los gobernantes serían elegidos por su capacidad intelectual, la cual, además, debería ser ampliamente demostrada.

En cuanto a la justicia, para Platón estáse estrechamente ligada a los distintos estamentos sociales; se cumpliría siempre que cada miembro de cada estamento desempeñe su función en él; por otra parte, Moro piensa en la justicia en términos de equidad; todo debe conseguirse siempre que la población total se vea beneficiada y obtenga lo que necesita en igual proporción, esto es, considerar la justicia como una especie de comunismo inicial.

Finalmente se llega a la concepción del ser humano: para Platón la naturaleza se encarga de diferenciar un individuo de otro; desde la concepción habrá quienes sentirán inclinación por la búsqueda de la sabiduría; otros, en cambio, nacerán para gobernar sobre los demás $\mathrm{y}$, asimismo, se hallarán los que nacen para dedicarse al trabajo, cualquiera que sea (principalmente agrícola). Contrario a esto, Moro argumenta que no existe diferencia entre los seres humanos y que todos, desde que nacen, tienen por condición primordial la libertad $\mathrm{y}$, sin excepción, todos vienen al mundo destinados a la grandeza, el cultivo de las virtudes y la consecución de la sabiduría.

Es posible notar cómo los preceptos platónicos sobre el ideal de una república hacen eco en lo propuesto por Moro. Ambos plantean sus utopías, sus Atlántidas, sus visiones particulares de un «buen lugar», irrealizable, pero imaginable y deseable. Tal como lo hará 
Carlos Gagini en su texto La caída del águila y como se verá en el siguiente apartado.

\section{Atlántida e isla del Coco: tradición clásica en la construcción del espacio utópico}

El desarrollo de una construcción discursiva, surgida a partir del acercamiento a las funciones de la utopía y de la renovación de temáticas clásicas para la construcción del espacio utópico en La caída del águila de Carlos Gagini, le permitió al autor tener más libertad narrativa ${ }^{29}$, en la medida en que podría presentar su inconformidad por la realidad histórica que vivía y el deseo del derrumbamiento del imperialismo, que mostrará, además, por la conjunción de esfuerzos entre alemanes, japoneses y centroamericanos.

Esta nueva construcción de la utopía se aleja de la forma tradicional (expuesta en El árbol enfermo), que presentaba la oposición contra el imperio en personajes realistas caracterizados y que le permitirían al narrador plantear los conflictos políticos de manera más abstracta, al utilizar un criterio más elástico de verosimilitud ${ }^{30}$. Gagini tendrá la posibilidad, sin limitaciones, de tratar su realidad histórica, de manera que su antiimperialismo no fuese una crítica hacia dentro, es decir, el imperialismo en Costa Rica o desde Costa Rica, sino que podría realizar su crítica hacia el exterior; esto es, como lo indica Quesada, enfrentando la voz de la oligarquía, del nacionalismo, y el humanismo latinoamericano contra la «voz imperialista» del utilitarismo estadounidense.

El discurso utópico, el apego al método experimental y a la ciencia como criterios de verdad y la adecuación de antiguos repertorios asociados con el Mundo Clásico, específicamente el mito de la

29 Álvaro Quesada, La voz desagarrada: La crisis del discurso oligárquico y la narrativa costarricense, 1917-1919 (San José: Editorial Universidad de Costa Rica, 1988).

30 Francisco Rodríguez Cascante, Imaginarios utópicos. Filosofía y literatura disidentes en Costa Rica 1904-1945 (San José: Editorial Universidad de Costa Rica, 2016). 
Atlántida, le permiten a Gagini construir un texto verosímil impregnado de ideología antiimperialista. En esa construcción discursiva del espacio utópico, la isla del Coco es la base en la que Los caballeros de la libertad ${ }^{31}$, pero, al mismo tiempo, como el espacio donde el ideal de un mundo mejor será una posibilidad auténtica. Es el sitio ideal, pues incluso Roberto Mora (el personaje de La caída del águila) reconoce que es difícil imaginar paraje más adecuado como refugio. Esa idea se refuerza con el recuerdo de que la isla fue escondite de piratas. La estrategia para la construcción de esta base utópicamente tecnologizada será la mímesis con el ambiente. La red de cavernas que Mora explora podría ocultar el arsenal que posee y, además, podrían albergar cómodamente más de un centenar de personas.

La Atlántida descrita en apartados anteriores, a partir de los diálogos de Timeo y Critias, se relaciona, mediante elementos de tradición clásica, con la isla del Coco, vista como un espacio utópico de avanzada por Carlos Gagini La caída del águila. Queda clara, en el imaginario de la creación de ambas islas (Atlántida e isla de Coco), una evocación a considerar la utopía, no solo como un simple lugar deseable, pero imposible, sino como la esperanza de un lugar ideal, donde el ser humano pueda realizarse, al vivir con equidad, respeto mutuo, comodidad y tranquilidad.

Por otra parte, en La caída del águila, Roberto Mora dice que hicieron «de esta isla el centro de nuestras operaciones» donde, además, «de absoluta libertad gozamos de todas las comodidades deseables» (73). Es posible comparar lo mencionado por el personaje con la Atlántida platónica, pues esta, al igual que la isla de Gagini, no depende de nada ni nadie más que de sus habitantes para funcionar (es autosuficiente). Además, se trata de un espacio cerrado, al que no se pude acceder fácilmente a menos de que haya un permiso especial de

31 Desde el inicio se presenta una utopía humanista manifiesta en el sentido de que Mora, el personaje principal, logra reunir aliados, también centroamericanos para perseguir un ideal: derrocar el imperialismo de los Estados Unidos. 
ingreso. En el pasaje 115 c de Critias se describe la complejidad orográfica de la isla y cómo es poco a poco organizada por sus pobladores:

En primer lugar, levantaron puentes en los anillos de mar que rodeaban la antigua metrópoli para abrir una vía hacia el exterior y hacia el palacio real. Instalaron directamente desde el principio el palacio real en el edificio del dios y de sus progenitores y, como cada uno, al recibirlo del otro, mejoraba lo que ya estaba bien, superaba en lo posible al anterior, hasta que lo hicieron asombroso por la grandeza y la belleza de las obras ${ }^{32}$.

Ambas islas constituyen paraísos, lugares utópicos donde vivires placentero y permite al ser humano lograr su plenitud. La isla remite al Edén; para Eliade (1996) la isla representa, a quien la habita, el centro del mundo, el lugar por donde pasa el axis mundi, es decir, el punto de partida, donde se enlaza el mundo terrenal con el mundo divino, donde los ideales son alcanzables. Teniendo en cuenta que Roberto Mora considera la isla del Coco como en "centro de las operaciones», al igual que la Atlántida, no solo representa la base para desarrollar un proyecto emancipador sino para la construcción de una sociedad ideal, justa y equitativa.

Desde las estructuras antropológicas del imaginario estudiadas por Durand (2004) $)^{33}$, la isla está vinculada a las ideas de reposo, intimidad y unión, a la vez que se encuentra muy ligada a la noción del retorno a los orígenes, a una situación primordial, tal como ocurre con la isla de La caída del águila, tal espacio geográfico no solo tiene como fin la construcción de una base estratégica, sino el retorno al origen, para erigir una nueva nación.

Hay otros puntos de encuentro entre la Atlántida y la Isla del Coco. Por un lado, se desconoce la ubicación geográfica de la Atlántida (Platón, Critias, pje. 113 c) y, no en vano, se ha convertido en uno de

32 Platón, Critias, 285.

33 Gilberd Durand, Estructuras antropológicas del imaginario (México: Fondo de Cultura Económica, 2004). 
los más grandes misterios. De la misma manera, la isla del Coco se describe como misteriosa, digna de ser explorada, pues se la califica de «agreste», «impenetrable» y «salvaje» (3). De esta manera, ambas islas se destacan por el desconocimiento que gira en torno a ellas.

Otro punto de encuentro son las descripciones de la arquitectura palaciega, pues Platón menciona la existencia de incontables palacios y describe la ciudad como un lugar de avanzada (Platón, Critias, 1992, pje $116 \mathrm{~d}$-e); Gagini ofrece descripciones que podrían ser figuraciones de los antiguos palacios atlánticos, por ejemplo, cuando se menciona que «Roberto guio a sus invitados a una especie de gruta, amueblada con lujo oriental y alumbrada por fanales de luz incandescente» (83). Asimismo, cuando Roberto Mora menciona:

¡La comida!-ordenó lacónicamente el ingeniero. Los sirvientes colocaron en el centro de la habitación una mesa que, en menos de un minuto, arreglaron suntuosamente. Fanny se creía transportada a uno de los lujosos hoteles de Nueva York. Gran cantidad de ostras y todos los mariscos de que abunda la isla, manjares preparados con arte exquisito, vinos de las mejores cepas; nada faltaba en el regio banquete (83).

La suntuosidad con que se describe el banquete y los lujos que disfrutan en esa isla solo es comparable con la de los palacios y templos griegos. La isla no solo es una Atlántida vista como espacio utópico, sino que lo es en cuanto desarrollo, lujo y ostentosidad, es decir, el alcance de la plenitud humana a partir del buen vivir de todos los seres que lo habitan, hecho que queda patente en el brindis que propone Roberto en dicho banquete, en que menciona «—Propongo un brindis por la futura libertar y fraternidad de todos los pueblos-》 (83). La utopía humanista es clara: la isla es un centro a partir del cual se buscará el bienestar de la población costarricense (centroamericana) y la emancipación del dominio imperialista, tal como afirma cuando Roberto Mora «contemplaba en su imaginación a las naciones unidas, no por la presión de la fuerza sino por los lazos del amor» (180). 
Otro punto de encuentro en el mito platónico y la isla descrita por Gagini es el uso de elementos verosímiles que la ubicarían como una posibilidad real, como un proyecto realizable. Por ejemplo, Gagini ubica su utopía en una isla conocida, presenta un proyecto nacionalista y liberador, contra una nación (Estados Unidos) y alía a Costa Rica con japoneses, que, como es sabido, a finales del siglo XIX no mantenían buenas relaciones diplomáticas con los EE. UU. Platón se vale de elementos reales para dotar de verosimilitud su invención, por ejemplo, algunas características contextuales y culturales y algunas guerras en las que se vieron envueltos contra los atenienses (Platón, Critias, pje. 118c-119b).

La Atlántida era descrita como una isla en la que se desarrolla una sociedad avanzada, lo mismo es posible notar cuando en La caída del águila se describe la base que se erige en la isla y la alta tecnología con que gozan:

Dos líneas paralelas de rieles, relucientes como hilos de plata, se dilataban en una extensión de más de un kilómetro y se perdían en el recodo formado por una colina (68).

Colocamos en la costa occidental nuestro aparato inalámbrico (71).

-Esa hierba--explicó el joven rubio, señalando a la que se extendía a un lado de la línea férreas artificial y tan perfectamente imitada que sólo las vacas son capaces de distinguirla de la natural. Está entramada en una red metálica que recubre la línea al oprimir un botón eléctrico. Cerca de las cuevas que habitamos hay otro tronco de cemento idéntico al que tiene Jiso para hacer desaparecer nuestras instalaciones en cualquier momento (73).

Estos submarinos navegan más de doscientos kilómetros por hora y pueden dar la vuelta al mundo sin necesidad de arribar a ningún puerto para proveerse de víveres o de combustible (78). 
Son varias las ocasiones en que las descripciones de la isla apuntan a una serie de avances tecnológicos que la igualarían en fuerza con la nación opresora y a partir de los cuales montará contra en función de alcanzar los ideales de libertad, fraternidad e igualdad.

Finalmente, es apreciable el parecido que existe entre ambas islas, pues las dos son descritas como vergeles utópicos, que proporcionan todo lo necesario para vivir bien. Platón (Critias, pjes 117 a 118 c) señala que la Atlántida es comparable con un paraíso natural, cuya tierra no solo le proporciona a sus habitantes todo lo que necesitan para comer, sino las condiciones óptimas en cuando a vivienda y protección; en La caída del águila, ninguna vida es más placentera que la que se vive ahí:

...ninguna vida podría ser más agradable que la de esta isla, en donde además de absoluta libertad gozamos de todas las comodidades deseables. Tenemos habitaciones casi lujosas, víveres en abundancia, nuestros pescadores nos traen diariamente ostras y gran variedad de pescados, nuestra vacada nos suministra leche, quesos y mantequilla, y la huerta toda clase de verduras y delicadas frutas. Distraemos nuestros ratos de ocio con la lectura de obras de una selecta biblioteca o tañendo instrumentos de música. que nos proporcionan deliciosas veladas. $(79-80)$

\section{Conclusiones}

La tradición clásica establece relaciones entre textos antiguos y modernos sin que sea necesaria la mención de elementos directos; es decir, sin que se acuda al paradigma positivista de texto clásico «A» en texto moderno «B». De ahí que sea posible relacionar la forma en la que Carlos Gagini desarrolla su espacio utópico en la isla del Coco, con la manera en que la Atlántida es descrita por Platón en los diálogos Timeo y Critias. Se debe tener en cuenta que el autor moderno puede emplear la tradición clásica en un texto, aunque no sea consciente del uso de pasajes míticos, o bien, de la incorporación de elementos 
clásicos (personajes, metáforas, ideas, nociones sobre diversos temas, posiciones filosóficas, entre otros) tomadas de textos clásicos (griegos o latinos), pues las estructuras míticas de su pensamiento hacen que, de forma inconsciente, las incorpore en la trama de la nueva producción

La Atlántida platónica comprende como modelo narrativo para la conformación de un ideal que serviría para mostrar cómo debería ser organizada una ciudad para su correcto funcionamiento y en la que sus habitantes puedan llegar a ser plenamente felices. El espacio utópico, tanto en el mito de la Atlántida como en la construcción de la base de los Caballeros de la Libertad, en la isla del Coco, está conformado en función de quienes habitan el lugar, de manera que la utopía, en ambos casos, se comprende como un proyecto comunal, en procura de la plenitud en todos los ámbitos de la vida.

El espacio geográfico, la organización social, la tecnificación del territorio, lo ignoto e inaccesible de este, son puntos de encuentro entre la descripción de la Atlántida y la isla del Coco. Sin duda, Gagini se vale derecurre al modelo de espacio utópico de Platón en Timeo y Critias, para edificar ficcionalmente una isla en la que los ideales de paz, libertad, fraternidad y progreso confluyeran y, a partir de la que se eliminasen eliminar a las fuerzas del imperialismo, en favor de la unificación centroamericana. 